\title{
EL CASO DE ARRIBA DE + MEDIO DE TRANSPORTE: SUBESPECIFICACIÓN Y ENCUADRE
}

\author{
Patricia C. Hernández \\ Universidad de Buenos Aires - Instituto de Lingüística \\ Instituto de Enseñanza Superior en Lenguas Vivas "Juan R. Fernández" \\ Instituto Superior del Profesorado "Dr. Joaquín V. González" \\ patrindez@yahoo.fr
}

\begin{abstract}
Resumen
Este artículo explica el uso de arriba de como locativo en vehículos considerados como contenedores. Nos serviremos de las nociones de localización, configuración, contenedor y soporte para describir el semantismo de en, dentro de, adentro de, sobre, encima de, arriba de. Un estudio cuantitativo y cualitativo de enunciados extraídos de Internet permitirá caracterizar arriba de cómo localizador concurrente con la preposición en. La distinción entre ambos relacionantes será modelizada como un fenómeno de encuadre visual: arriba de presupone elipsis de movimiento ascendente.
\end{abstract}

PALABRAS CLAVE: localización, configuración, contenedor, soporte, preposición

\begin{abstract}
This paper explains the usage of the expression arriba de as a locative in vehicles conceptualized as containers. Notions of localization, configuration, container and support enable us to describe the semantic properties of en, dentro de, adentro de, sobre, encima de, arriba de. A quantitative and qualitative study of utterances taken from the web allows us to characterize arriba de as a locative in competition with preposition en. The distinction between both markers is explained as a phenomenon of visual framing: arriba de presupposes the ellipsis of an upward movement.
\end{abstract}

KEY WORDS: localization, configuration, container, support, preposition

Amigos foreros: ¡Agradezco mucho sus respuestas! Han sido muy interesantes. Sería aún más interesante leer la opinión de algún argentino, ya que solamente Zumac (de México) concordó que "vivo arriba de un café" suena bien. Les juro que en la Argentina yo solía escuchar al sonar el teléfono de alguien, "No puedo hablar ahora, estoy arriba del colectivo/del micro"

John Date Feb 2006. Pittsburgh. U.S.A. Native language USA English

Word Reference Forums/Spanish-English

\section{Introducción}

En el presente trabajo, nos ocuparemos de un caso de indicación espacial característico del español de Hispanoamérica, particularmente de Argentina, que parece desafiar las condiciones de verdad: la fórmula arriba de + medio de 
transporte para indicar interioridad. Así, si, a punto de salir de vacaciones, alguien que está disponiendo el equipaje en el automóvil produjera el enunciado

(1) La valija está arriba del auto

éste podría suscitar dos lecturas:

(2) La valija está en el portaequipajes (ubicado en el techo del auto)

(3) La valija está en el baúl / en el asiento trasero del auto

La primera interpretación responde referencialmente a las condiciones de verdad y describe una configuración espacial de superposición. La segunda, de naturaleza pragmática, corriente en el habla rioplatense, apela a datos contextuales y tiende simplemente a localizar la valija en el vehículo. Esto parece indicar que la locución arriba de posee, al igual que otros elementos relacionantes, según los usos, más de un nivel de especificación en el español de Hispanoamérica.

Nuestro análisis se centrará en enunciados correspondientes a la segunda interpretación, con subespecificación de la configuración espacial típica e inferencia pragmática de localización, incluso en contenedores.

No analizaremos en esta oportunidad los sujetos inanimados (como el ejemplo de la valija); nuestro estudio se centrará en la localización de sujetos animados humanos mediante sintagmas preposicionales con determinante. Asimismo, dejaremos momentáneamente de lado los verbos de movimiento ("voy arriba del avión", "ando arriba del auto") para concentrarnos en los casos de coocurrencia con verbos situativos, ejemplificados por la secuencia "estoy arriba del avión".

Nuestra reflexión se ubica dentro del enfoque cognitivo-prototípico que asocia verbalización y rutinas cognitivas: anclado en nuestra matriz cognitiva general, el lenguaje se encuentra en estrecha relación con la percepción visual y el sistema motor (Jackendoff, 1983). El empleo discursivo de los marcadores espaciales no escapa a esta interacción. De allí el interés, para el estudio de los relacionantes seleccionados, de descompartimentar sistema verbal y puesta en imagen (Ver sección 5.2.).

En lo que respecta a la reflexión a nivel semántico, partimos, conceptualmente, de la existencia de categorías no discretas, con fronteras difusas, en las que el valor de las unidades lingüísticas se determina por confluencia de propiedades según un parecido de familia (Wittgenstein, 1953). Los marcadores espaciales aparecerán pues en un continuum en el que se observarán tendencias según el análisis de las formas lingüísticas en contexto. Un elemento fundamental de nuestro estudio será la estrecha relación entre semántica y pragmática: la elección por el hablante del relacionante arriba de se considerará motivada y será objeto de una modelización en términos de encuadre. 
Nuestro estudio se organizará del siguiente modo: tomando como marco teórico específico el tratamiento de las preposiciones realizado por Claude Vandeloise $(1986,1990)$ abordaremos la diferencia entre localización y configuración para centrarnos, luego, en las relaciones funcionales de contenedor y soporte. Tras una breve presentación del semantismo de los relacionantes espaciales típicos asociados a ambas nociones, procederemos al análisis de nuestro corpus de datos. Este estudio nos permitirá constatar la emergencia de la secuencia estar arriba de + medio de transporte. Para la explicación de este empleo nos serviremos del concepto de escena verbal (Victorri y Fuchs, 1996). Finalmente haremos mención a la pregnancia cognitiva del movimiento ascendente.

\section{Presentación general de la espacialización sugerida por los elementos relacionantes}

2. 1. La verbalización de las relaciones espaciales

La representación de escenas espaciales mediante un sistema discreto y lineal, se caracteriza por una relativa reducción descriptiva (De Vega y Rodrigo, 1997: 59). En efecto, mientras la ostensión se encuadra dentro de la continuidad del espacio, la verbalización supone la segmentación y categorización de las entidades de referencia relacionadas mediante marcadores espaciales. La puesta en palabras supone por tanto una esquematización según las estructuras gramaticales de la lengua (Talmy, 1983: 258). Éstas seleccionan ciertos aspectos de las escenas dejando en sombra otros. El locutor, elige entonces según un principio de representatividad (Talmy, 1983: 279). Por su plasticidad, estos esquemas, como señala Guillermo Soto (1996: 41), admiten extensiones y especificaciones. Tales modificaciones parecen responder a lo que Annette Herskovits (1985: 361-367) define como casi-principios pragmáticos (pragmatic near principels):

- saliencia, es decir apreciación de partes salientes en la conceptualización de los objetos según la interacción con el medio. Este criterio, que incluye fenómenos de naturaleza metonímica, se encontrará también en la teoría de las zonas activas de Ronald Langacker (1987);

- pertinencia durante el intercambio de información: se elegirá el esquema que evoque la situación espacial de modo más pertinente según los objetivos de la comunicación;

- tolerancia para aceptar una cierta imprecisión en la definición de ángulos, distancia, inclusión parcial, etc.;

- tipicidad que permite asignar a una relación locativa una información espacial no explícita pero característica. En este aspecto juegan ciertas configuraciones canónicas. 
Saliencia, pertinencia, tolerancia y tipicidad permiten compensar cierta imprecisión en las indicaciones espaciales que se rigen asimismo por un criterio de economía según la máxima de cantidad de los principios de cooperación (Grice, 1979: 61).

Es decir que una descripción lingüística del espacio, tal como lo afirma Claude Vandeloise (1986: 11-30), dista de coincidir con las representaciones puramente geométricas o topológicas. En su estudio de las preposiciones de lugar, el autor de L'espace en français (1986) propone la noción de relación funcional a partir de nuestra interacción con nuestro entorno: la puesta en palabras de las relaciones espaciales explota al máximo el conocimiento de los interlocutores sobre la función de las entidades, sus posiciones canónicas, las rutinas instituidas, la física ingenua (importancia de la ley de gravedad, noción de soporte y de contenedor). Este saber compartido constituye, afirma Vandeloise, "la trama indispensable en la que se inscribe el lenguaje" (1986: 21).

Veremos que, en el caso de ciertas interpretaciones pragmáticas de la formulación estar arriba de + medio de transporte, el conocimiento compartido sobre situaciones espaciales canónicas y la pertinencia de la relación entre figura y base permitirán una lectura cooperativa y tolerante de los esquemas activados por la verbalización.

\subsection{Localización vs. configuración}

Claude Vandeloise (1990) define la localización como una referencia abstracta dependiente del conocimiento compartido y las rutinas sociales. Este saber, central para la producción de inferencias, permite una subespecificación a nivel preposicional: las preposiciones convocadas por los enunciados de localización suelen considerarse como abstractas o incoloras, con menor substancia semántica.

En cambio la configuración, más independiente de los mecanismos inferenciales, constituye una operación descriptiva que codifica más explícitamente la escena espacial y provee un mayor grado de detalle. En esta operación suelen participar preposiciones denominadas coloreadas, es decir con un aporte propio más substancial en la codificación de la relación.

\subsubsection{La preposición en como relacionante localizador}

Para ilustrar la diferencia entre ambas relaciones espaciales, analizaremos los siguientes ejemplos:

(4) El frasco de perfume está en la cómoda

(5) El frasco de perfume está dentro de la cómoda

(6) El frasco de perfume está sobre la cómoda 
En (4), el elemento localizador no brinda detalles: el frasco puede estar tanto dentro de uno de los cajones de la cómoda como encima del mueble junto a un portarretratos. Por tal motivo consideramos que, en este enunciado, la preposición en marca localización y construye un espacio sin descripción gracias al conocimiento común. En este caso, la preposición puede alternar con indicadores tanto de interioridad (dentro de) como de superposición (sobre). Por su polivalencia relacional, tiende pues a la abstracción como parecen sugerirlo, asimismo, sus múltiples traducciones y su dependencia contextual. En (5) y (6), se observan dos configuraciones espaciales divergentes: interioridad (dentro de) y superposición (sobre), excluyentes entre sí.

La misma diferencia existe cuando se trata de un sujeto humano. El enunciado

(7) Pablo está en la cama

no induce configuración espacial: podemos imaginar a Pablo tanto dentro de la cama, debajo de las cobijas, como recostado sobre ella, vestido. La ambigüedad se despejará gracias al contexto. Es decir que, como relacionante, la preposición en admite diferentes grados de especificación: marcador de localización a-descriptivo, puede sugerir una relación de interioridad, alternando con dentro de o de superposición conmutando con sobre.

Resumiendo: los usos prepositivos pueden interpretarse como localizadores -con bajo coeficiente descriptivo y alta dependencia contextual- o configuracionales -con alto coeficiente descriptivo y menor dependencia del entorno-. Lejos de ser rasgos excluyentes, ambas nociones se ubican como polos de un continuum de espacialización.

Localización y configuración nos permitirán una caracterización de los relacionantes objeto de nuestro estudio y fundamentalmente, una distinción entre la preposición en, en el polo de la localización, y los demás marcadores espaciales analizados, de mayor valor configuracional. Identificamos dos relaciones funcionales de configuración: la interiorización y la superposición.

\subsection{La relación configuracional de interiorización}

En L'espace en français, Claude Vandeloise (1986: 222-228) propone un análisis funcional de la interiorización sobre la base de nuestro conocimiento del mundo y plantea la relación en términos de continente/contenido (contenant/contenu). La base u objeto de referencia actúa como contenedor, la figura ${ }^{1}$

1 Seguimos la terminología de Cifuentes Honrubia (1996: 25). Claude Vandeloise (1986) emplea los términos cible (figura) y site (base). 
o entidad a situar se encuentra contenida en la base. Tal relación posee rasgos constitutivos: la base controla la posición de la figura, la figura se desplaza hacia la base, existe inclusión (al menos parcial) de la figura en la base.

Estos rasgos, que Vandeloise emplea para caracterizar la preposición francesa dans, pueden aplicarse tanto a la preposición en como a los configuradores espaciales dentro de y adentro de.

\subsubsection{Los elementos relacionantes dentro de / adentro de}

Construidas a partir de los adverbios dentro y adentro, las locuciones dentro de y adentro de inducen interioridad. Cifuentes Honrubia (1996: 149) establece una distinción entre ambas expresiones: en su origen, dentro acompañaba verbos estáticos y adentro (a+dentro) verbos de movimiento con matiz de dirección. En la actualidad, dentro supone un contenedor limitado mientras que adentro parece designar el espacio de modo más indeterminado. Aunque en el discurso estos empleos puedan alternar, cabe señalar que ambas locuciones prepositivas aparecen como indicadores de interioridad más precisos que la preposición en.

El análisis de nuestro corpus sobre relacionantes + medio de transporte permitirá apreciar la configuración de interioridad inducida por dentro de y adentro de en oposición a la localización asociada al empleo de la preposición en.

\subsection{La relación configuracional de superposición}

Claude Vandeloise (1986: 194) trata la noción de superposición mediante la relación funcional portador/portado (porteur/porté) en la cual la base actúa como soporte de la figura. Esta relación se caracteriza por los siguientes rasgos: la base, que se opone a la acción de la gravedad, suele ser más grande que la figura, se encuentra a una altura inferior y está a menudo oculta por ella. Ambas se encuentran generalmente en contacto. Esta relación funcional de configuración, asociada en francés al empleo de la preposición sur, puede ser inducida, en español, por los términos sobre, encima de y arriba de.

Antes de tratar estos tres relacionantes de modo global, haremos algunas consideraciones con respecto al uso de la locución arriba de.

\subsubsection{El empleo de arriba de como locución prepositiva}

Comenzaremos por una somera presentación según diccionarios y tratados de normativa. Indicador de verticalidad, el adverbio arriba admite usos estativos y dinámicos.

Como expresión de carácter estático, arriba indica, según María Moliner, un "lugar más alto que aquel en que está el que habla" tanto en sentido con- 
creto ("Mi hermano vive arriba") como, metafóricamente, para indicar una posición social elevada ("Los que están arriba no se acuerdan de los miserables"). José Luis Cifuentes Honrubia pone énfasis en la indicación de superposición y distancia (que opone a la superposición y contacto inducida por encima). Con arriba, afirma el lingüista (1996: 102), localizamos el extremo superior del eje vertical de un objeto localizante, eje que se construye con dos elementos en oposición arriba-abajo.

En empleo dinámico, arriba indica movimiento explícito o implícito hacia lo alto ("Río arriba") o funciona incluso como interjección en sentido literal o figurado (“iArriba!”/ “Arriba los ánimos!”) para estimular a levantar algo o levantarse. Según Cifuentes Honrubia (1996), el adverbio articula el término meta de la expresión direccional.

Las obras de consulta centran su estudio en el empleo adverbial descripto ut supra y, en general, dedican menor atención a su empleo en combinación con la preposición de. María Moliner no consigna su uso como locución preposicional salvo en frases generalmente negativas ("No tiene arriba de 20 años"). Por su parte, el Diccionario de la Real Academia Española y el Diccionario Panhispánico de dudas (en línea), señalan que "en el español de América, en registros coloquiales o populares, no es infrecuente que arriba vaya seguido de un complemento con de: "Le dejó unas revistas del corazón arriba de la cama» (Guambia [Ur.] 27.3.04)". Esta formulación aparece estigmatizada como "uso rechazado por los hablantes cultos" y se recomienda el empleo de encima. La misma descripción según José Luis Cifuentes Honrubia (1996: 90), quien pone énfasis en la diferencia de gramaticalización existente entre encima y arriba: mientras el uso de encima de como locución preposicional se encuentra extendido e instituido, arriba de permanece asociado a un empleo exclusivamente adverbial. En efecto, en la continuidad entre unidades léxicas y gramaticales se identifican diferentes niveles de fijación dentro de un proceso con diferentes estadios (sustantivo>adverbio>preposición). Encima de se ubicaría, consigna el autor, como preposición, en la fase final del proceso y arriba, como adverbio, en el segundo estadio (1996: 103).

Más tarde, en Locuciones prepositivas. Sobre la gramaticalización preposicional en español (2003), Cifuentes Honrubia, que trata aún el uso preposicional (arriba de la casa) como forma vulgar o incorrecta, considera estos empleos como indicadores de gramaticalización. En el cuadro general sobre índices combinatorios (2003: 230), el lingüista caracteriza la locución según pruebas de funcionamiento preposicional entre las cuales, para el tema que nos ocupa, destacamos la equivalencia en el plano semántico con una preposición simple ( arriba de $=$ sobre). 
Con respecto a la evolución arriba>arriba de, cabe señalar la existencia de cadenas de gramaticalización organizadas según un parecido de familia con solapamientos y coexistencia de formas entre un uso fuente, más histórico, con menor gramaticalización y un uso meta, más gramaticalizado (Cifuentes Honrubia, 2003: 32-33). Tal proceso de gramaticalización parece en curso en la comunidad lingüística hispanoamericana en la que la locución arriba de se encuentra instalada en el discurso cotidiano dentro del grupo de indicadores de superposición.

(8) Le dejó unas revistas del corazón sobre / encima de larriba de la cama

Comportándose semánticamente como marcador de superposición en alternancia con sobre/encima de, arriba de hereda, de su empleo adverbial, usos estativos ("José vive arriba" / "José vive arriba de la oficina") y dinámicos ("José camina arriba" / "José camina arriba de la alfombra"). Con respecto a la implicación de movimiento de la expresión en su uso adverbial, existe afinidad semántica entre arriba y el verbo subir. Es el caso de ¡Arriba! para estimular a levantar algo o levantarse. O incluso, subir a un medio de transporte. A tal punto que el uso coincidente suscita una redundancia (subir arriba / subir arriba de la escalera). Dany Laur (1993: 53-57) denomina tal afinidad como empleos congruentes: hay congruencia entre verbos y preposiciones, por ejemplo, cuando la coocurrencia produce redundancia, y no congruencia cuando la preposición aparece como autónoma. Volveremos sobre este tópico en la sección 5.2.3. Tal como lo hemos mencionado en la introducción, nuestro estudio se centrará en los empleos estativos en coocurrencia con el verbo estar. La combinación de la locución prepositiva con verbos dinámicos será objeto de un estudio particular en próximos trabajos.

Como veremos más adelante, la incipiente desemantización de arriba de (su subespecificación evidenciada por su coocurrencia con contenedores) y la ampliación de su uso (indicación de superposición y de localización en interiores) constituyen indicios de gramaticalización de esta forma lingüística.

\subsubsection{Los elementos relacionantes sobre, encima de, arriba de}

Desde el punto de vista semántico, arriba de comparte una zona de afinidad con sobre y encima de para el marcado de la superposición. Los tres términos suelen indicar altura superior aunque aparecen divergencias en la literatura con respecto a rasgos de distancia y contacto ${ }^{2}$. En el caso de sobre, María Luisa López (1972: 141) identifica

2 Según Miller \& Johnson-Laird (1976: 61), los objetos discretos x e y se dicen en contacto si hay por lo menos una parte de la superficie de $x$ a distancia cero de una parte cualquiera de la superficie de $y$. 
- un uso mayoritario de sobre con implicación de contacto: la taza está sobre la mesa

- un uso marginal de sobre sin implicación de contacto: el árbol está inclinado sobre el río

La expresión encima de marca la situación de una entidad que se encuentra situada a un nivel superior a otra sobre la misma línea vertical y en contacto con ella, por ejemplo encima de la mesa, la nariz está encima de la boca. García Pelayo y Gross \& Testas (1967) señalan que encima suplanta a sobre cuando el objeto superpuesto se encuentra ubicado a cierta altura.

José Luis Cifuentes Honrubia (1996) considera que encima de puede marcar superposición con y sin contacto. Sin embargo, mientras que con la preposición sobre, la figura no debe encontrarse necesariamente sobre el eje vertical (un cuadro sobre una pared), con encima de, esta coincidencia es obligatoria. El autor señala además que la intensidad del contacto difiere de una expresión a otra: sobre establece un contacto físico más fuerte al punto que figura y base parecen más cohesionados. El lingüista (1996: 108) evoca la distinción de Gili Gaya (1973) en su diccionario de sinónimos: mientras que encima explica la situación local de un cuerpo con respecto al que se encuentra abajo, la preposición sobre representa no solo la situación sino también y sobre todo el peso de un cuerpo sobre otro. Esta caracterización se encuentra también en las reflexiones de Bernard Pottier (1997: 33) quien alude a la fuerza de la gravedad que un cuerpo ejerce sobre otro, tal como lo señala Joseph López de la Huerta en su Examen de la posibilidad de fixar la significación de los sinónimos de la lengua castellana (1789: 100-102) -la oposición a la gravedad será asimismo un rasgo pertinente para el empleo de la preposición francesa sur según Claude Vandeloise (1986)-. Cifuentes Honrubia destaca que este efecto genera una impresión de cohesión entre las dos entidades en relación que aparecen más estrechamente unidas.

Dicho esto, sobre y encima de funcionan en el discurso del locutor ingenuo como sinónimos (Cifuentes Honrubia 1996: 107) con los dos efectos de sentido: contacto o distancia.

En cambio, arriba de, marcando la localización sobre un eje vertical con noción de distancia entre figura y base no designa, en principio, situación de contacto. Sin embargo, en Hispanoamérica, como lo señala Guillermo Soto (1996: 39), un enunciado como "la lámpara está arriba de la cama" admite dos interpretaciones:

- sin contacto: la lámpara pende del techo

- con contacto: la lámpara se encuentra posada sobre la cama. 
Existen pues usos sinonímicos de arriba de y sobre indicando contacto como lo indican los siguientes ejemplos:

(9) me pareció mejor acostarme SOBRE el fogón (pág. 50)

(10) yo estaba despierta, arrinconada ARRIBA DEL fogón y temblando de miedo (pág. 51)

Sábato, E. (1973): Sobre héroes y tumbas. Buenos Aires: Editorial Sudamericana.

De estas consideraciones se desprende una representación en paralelo de los tres términos de superposición:

\begin{tabular}{|c|c|}
\hline Contacto: & SOBRE \\
\hline & \\
\hline
\end{tabular}

Los paréntesis indican la posibilidad de ocurrencias en el caso de empleos no canónicos.

\section{Nuestro corpus de estudio}

Según las necesidades concretas de nuestra investigación, hemos utilizado material disponible en la red -Web as Corpus (Rojo: 2010)- por su riqueza, variedad y fundamentalmente como fuente de datos para el estudio de esta expresión difícil de documentar satisfactoriamente mediante corpus habituales a causa de su baja frecuencia -característica del inicio de procesos de evolución, en el caso que nos ocupa, la gramaticalización de arriba de en el español de Hispanoamérica.

A título de ejemplo, una búsqueda en el corpus CREA (Corpus de referencia del español actual de la Real Academia Española) arroja magros resultados: no se registran casos para las secuencias arriba del avión/colectivo/micro o arriba de la bici. La formulación arriba del auto totaliza cuatro casos: dos en un periódico de Argentina en 1997, uno en la prensa de Chile en el mismo año y uno en una novela chilena publicada en 2001. Arriba del tren aparece en tres oportunidades: una en la prensa salvadoreña con fecha 2004, una en la prensa argentina en 1991 y una en un blog también de Argentina en 2003. En cuanto a arriba de la moto, se reporta una sola ocurrencia en una novela mejicana publicada en 1990 .

Aunque reconocemos las limitaciones de los buscadores comerciales (Cf. 4.2.), nuestra búsqueda nos ha permitido verificar la "vitalidad" de los usos a estudiar en el lenguaje cotidiano.

¿Cuál ha sido nuestra metodología para la recolección de datos? Buscamos en la Web la frecuencia de la expresión "estoy" (implicando sujetos animados humanos con verbos situativos) seguida de preposición o locución prepositiva 
y sintagmas compuestos por determinante + designación de medio de transporte. Se trabajó con dos buscadores (Yahoo y Google entre el 23 y el 27 de julio de 2009) para obtener más variedad en los resultados. Tomamos nota de la frecuencia de la expresión y copiamos las primeras 50 ocurrencias disponibles para tener elementos de juicio a nivel cualitativo. En algunos casos, los buscadores mostraron menos de esta cantidad.

Se buscaron los siguientes relacionantes:

- la preposición en, de empleo localizador general;

- las locuciones dentro de y adentro de, configuradoras de interioridad;

- la preposición sobre y las locuciones encima de y arriba de, configuradoras de superposición.

Los sintagmas nominales empleados como objeto preposicional corresponden, por las características de sus referentes, a:

- vehículos con habitáculo y puertas, asimilables a contenedores: avión, tren, micro, colectivo ${ }^{3}$, auto;

- vehículos sin habitáculo, asimilables a soportes ${ }^{4}$ : moto, bici.

\section{Análisis de datos}

\subsection{Análisis cuantitativo}

Se registraron variaciones en los resultados obtenidos en los dos buscadores comerciales utilizados. Los presentamos pues por separado. Los resultados obtenidos en Yahoo fueron los siguientes (se presenta el orden de frecuencias en porcentajes aproximados discriminando por buscador) (ver cuadro 1).

Según las frecuencias registradas, la preposición en ocupa la primera posición en coocurrencia con todos los medios de transporte aunque se perciben diferencias de comportamiento en combinación con contenedores y soportes. Con contenedores, el porcentaje de frecuencia de en se ubica holgadamente por sobre el $80 \%$ de las ocurrencias. Con soportes, el porcentaje de empleos es inferior al $50 \%$ y la suma de sobre y encima de puede aproximarse o incluso sobrepasar el total de usos de la preposición en.

3 En la Argentina, el término micro designa los ómnibus de larga distancia, por oposición a colectivo que refiere a los autobuses urbanos.

4 A este respecto, el español no manifiesta divergencia en la conceptualización de los vehículos cerrados como puede ocurrir en otros idiomas. Talmy (1983: 262-263) advierte que en inglés, la relación entre un viajero y un vehículo toma diferentes formas según se trate de un auto o de un ómnibus: el auto es conceptualizado como un espacio cerrado y exige el empleo de la preposición in (in the car) mientras que el ómnibus es aprehendido como una plataforma y convoca el uso de un marcador de superposición (on the bus). 


\begin{tabular}{|c|c|c|c|c|c|c|}
\hline \multicolumn{7}{|c|}{ Yahoo 23-27 de julio de 2009} \\
\hline Avión & Tren & Micro & Colectivo & Auto & Moto & Bici \\
\hline $\begin{array}{l}\text { En } \\
88,83\end{array}$ & $\begin{array}{l}\text { En } \\
97,45\end{array}$ & $\begin{array}{l}\text { En } \\
97,44\end{array}$ & $\begin{array}{l}\text { En } \\
90,63\end{array}$ & $\begin{array}{l}\text { En } \\
83,47\end{array}$ & $\begin{array}{l}E n \\
43,94\end{array}$ & $\begin{array}{l}\text { En } \\
49,55\end{array}$ \\
\hline $\begin{array}{l}\text { Arriba de } \\
4,71\end{array}$ & $\begin{array}{l}\text { Arriba de } \\
1,30\end{array}$ & $\begin{array}{l}\text { Arriba de } \\
2,28\end{array}$ & $\begin{array}{l}\text { Arriba de } \\
5,11\end{array}$ & $\begin{array}{l}\text { Arriba de } \\
9,86\end{array}$ & $\begin{array}{l}\text { Encima de } \\
26,52\end{array}$ & $\begin{array}{l}\text { Encima de } \\
31,25\end{array}$ \\
\hline $\begin{array}{l}\text { Dentro de } \\
4,49\end{array}$ & $\begin{array}{l}\text { Dentro de } \\
0,68\end{array}$ & $\begin{array}{l}\text { Dentro de } \\
0,28\end{array}$ & $\begin{array}{l}\text { Dentro de } \\
3,98\end{array}$ & $\begin{array}{l}\text { Dentro de } \\
5,41\end{array}$ & $\begin{array}{l}\text { Sobre } \\
24,24\end{array}$ & $\begin{array}{l}\text { Sobre } \\
13,39\end{array}$ \\
\hline $\begin{array}{l}\text { Sobre } \\
1,64\end{array}$ & $\begin{array}{l}\text { Adentro de } \\
0,47\end{array}$ & $\begin{array}{l}\text { Adentro de } \\
\text { Sobre/ } \\
\text { Encima de } 0\end{array}$ & $\begin{array}{l}\text { Adentro de } \\
0,28\end{array}$ & $\begin{array}{l}\text { Adentro de } \\
0,95\end{array}$ & $\begin{array}{l}\text { Arriba de } \\
5,30\end{array}$ & $\begin{array}{l}\text { Arriba de } \\
5,80\end{array}$ \\
\hline Adentro de 0,22 & $\begin{array}{l}\text { Encima de } \\
0,10\end{array}$ & & $\begin{array}{l}\text { Sobre/ } \\
\text { Encima de } 0\end{array}$ & $\begin{array}{l}\text { Sobre/ } \\
\text { Encima de } \\
0,16\end{array}$ & $\begin{array}{l}\text { Dentro de/ } \\
\text { Adentro de } 0\end{array}$ & $\begin{array}{l}\text { Dentro de } \\
\text { Adentro de } 0\end{array}$ \\
\hline Encima de 0,11 & $\begin{array}{l}\text { Sobre } \\
0\end{array}$ & & & & & \\
\hline
\end{tabular}

Cuadro 1. Resultados en Yahoo

Cabe señalar la aparición del relacionante arriba de en una proporción no desdeñable. Paradójicamente, este marcador de superposición ocupa la cuarta posición en coocurrencia con soportes y el segundo lugar en combinación con contenedores, desplazando al marcador prototípico dentro de.

\begin{tabular}{|l|l|l|l|l|l|l|}
\hline \multicolumn{9}{|c|}{ Google 23-27 de julio de 2009 } \\
\hline \multicolumn{1}{|c|}{ Avión } & \multicolumn{1}{|c|}{ Tren } & \multicolumn{1}{c|}{ Micro } & \multicolumn{1}{c|}{ Colectivo } & \multicolumn{1}{c|}{ Auto } & \multicolumn{1}{c|}{ Moto } & \multicolumn{1}{c|}{ Bici } \\
\hline En & En & En & Dentro de & Dentro de & Arriba de & Encima de \\
87,83 & 75,79 & 91,03 & 70,42 & 46,83 & 36,89 & 48,44 \\
\hline Arriba de 10,78 & Dentro de & Arriba de & En & En & Encima de & Arriba de \\
& 18,62 & 8,90 & 22,11 & 41,62 & 33,82 & 34,65 \\
\hline Dentro de & Arriba de & Dentro de/ & Arriba de & Arriba de 11, & Sobre & Sobre \\
1,34 & 5,58 & Adentro de 0,03 & 4,46 & 51 & 27,99 & 15,52 \\
\hline Sobre & Adentro de & Sobre/ & Adentro de & Adentro de & En & En \\
0,03 & 0,01 & Encima de 0 & 0,01 & 0,03 & 1,29 & 1,40 \\
\hline Adentro de 0,01 & Encima de & & Sobre/ & Sobre/ & Dentro de/ & Dentro de/ \\
& 0 & & Encima de 0 & Encima de 0 & Adentro de 0 & Adentro de 0 \\
\hline Encima de 0,01 & Sobre & & & & \\
& 0 & & & & \\
\hline
\end{tabular}

Cuadro 2. Resultados en Google

La supremacía de en parece puesta a prueba en Google. Con soportes, el locativo abstracto aparece con escasa frecuencia. Los relacionantes más empleados son los configuradores prototípicos encima de y arriba de seguidos de la preposición sobre, de menor frecuencia.

En combinación con contenedores, la preposición ocupa la primera posición con avión, tren y micro y la segunda con colectivo. Este último término constituye un caso especial: la expansión de su uso para designar un grupo de personas organizadas en torno a un proyecto común influye notablemente en la selección preposicional (ver 4.2.2.).

La aparición más marcada de la locución dentro de relega a arriba de a una tercera posición con contenedores, aunque el porcentaje de empleos (arriba del avión 10,78\%, arriba del micro 8,90\%, arriba del auto 11,51\%) merece reflexión. En coocurrencia con soportes, arriba de se sitúa en primero y segundo lugar. 
Es decir que el análisis cuantitativo de los datos disponibles, con variaciones según el buscador, permite apreciar la implantación de la locución arriba de no solo en coocurrencia con vehículos conceptualizados como soportes sino -y esto es lo más interesante- con vehículos considerados como contenedores.

\subsection{Análisis cualitativo}

Hemos limitado nuestro análisis cualitativo a los resultados obtenidos en Google pues los resultados reportados por Yahoo no brindaban un co-texto suficientemente completo. La lectura de las ocurrencias disponibles sugiere las siguientes observaciones:

- el total de ocurrencias señaladas por el buscador no puede ser considerado como dato científico ya que se registran repeticiones de enunciados;

- el número de ocurrencias disponibles es sensiblemente inferior a la cifra exhibida por el buscador como total de empleos.

Por tal motivo, los datos obtenidos serán tomados solamente como indicador de tendencia. A continuación se presenta el cuadro de datos con las cifras reportadas por Google, las ocurrencias efectivamente consultables y los enunciados seleccionados, una vez depurado el corpus de repeticiones o sentidos no pertinentes (ver cuadro 3).

A nivel cualitativo, observaremos el entorno inmediato de las expresiones analizadas con el objeto de identificar rasgos localizadores y/o configuracionales. A ello se sumará el relevamiento de marcas que puedan echar luz sobre el comportamiento semántico-pragmático de cada relacionante.

\subsubsection{La preposición en + medio de transporte}

Observamos (cuadro 4), que, cuantitativamente, con variantes entre los dos buscadores, el locativo abstracto en ocupa, en general, una posición central, con un elevado número de ocurrencias en combinación con casi todos los medios de transporte. Aparece en última posición con moto y bici en Google pero en primera en Yahoo.

A nivel cualitativo, vale señalar, en su comportamiento semántico, un claro matiz de localización: en interviene en enunciados de indicación geográfica o de destino del viaje con todos los medios de transporte:

(11) Yo estoy en el avión, volando entre París y Amsterdam, ¿y tú? ${ }^{5}$

(12) Estoy en el micro que me va a llevar de Cuernavaca a San Miguel de Ayende, el micro salió a las 5:15 de la mañana, habíamos trabajado hasta las 11,

5 Se reproducen la ortografía y puntuación de los originales. 


\begin{tabular}{|c|c|c|c|c|}
\hline Relacionante & SN & $\begin{array}{c}\text { Ocurrencias } \\
\text { reportadas } \\
\text { por el } \\
\text { buscador }\end{array}$ & $\begin{array}{l}\text { Ocurrencias } \\
\text { disponibles }\end{array}$ & $\begin{array}{c}\text { Ocurrencias } \\
\text { pertinentes }\end{array}$ \\
\hline \multirow[t]{7}{*}{$e n$} & el avión & 12.300 & 50 & 48 \\
\hline & el tren & 22.800 & 50 & 44 \\
\hline & el micro & 2.740 & 50 & 30 \\
\hline & el colectivo & 2.050 & 50 & 43 \\
\hline & el auto & 12.800 & 50 & 47 \\
\hline & la moto & 797 & 35 & 32 \\
\hline & la bici & 395 & 37 & 35 \\
\hline \multirow[t]{7}{*}{ dentro de } & el avión & 188 & 31 & 27 \\
\hline & el tren & 5.600 & 15 & 13 \\
\hline & el micro & 1 & 1 & 1 \\
\hline & el colectivo & 5.750 & 12 & 1 \\
\hline & el auto & 14.400 & 24 & 21 \\
\hline & la moto & 0 & 0 & 0 \\
\hline & la bici & 0 & 0 & 0 \\
\hline \multirow[t]{7}{*}{ adentro de } & el avión & 2 & 2 & 2 \\
\hline & el tren & 2 & 2 & 1 \\
\hline & el micro & 1 & 1 & 1 \\
\hline & el colectivo & 1 & 1 & 1 \\
\hline & el auto & 10 & 10 & 10 \\
\hline & la moto & 0 & 0 & 0 \\
\hline & la bici & 0 & 0 & 0 \\
\hline \multirow[t]{7}{*}{ sobre } & el avión & 4 & 4 & 3 \\
\hline & el tren & 0 & 0 & 0 \\
\hline & el micro & 0 & 0 & 0 \\
\hline & el colectivo & 0 & 0 & 0 \\
\hline & el auto & 1 & 1 & 1 \\
\hline & la moto & 17.300 & 18 & 16 \\
\hline & la bici & 4.930 & 22 & 21 \\
\hline \multirow[t]{7}{*}{ encima de } & el avión & 1 & 1 & 1 \\
\hline & el tren & 1 & 1 & 1 \\
\hline & el micro & 0 & 0 & 0 \\
\hline & el colectivo & 0 & 0 & 0 \\
\hline & el auto & 1 & 1 & 1 \\
\hline & la moto & 20.900 & 31 & 27 \\
\hline & la bici & 13.700 & 31 & 27 \\
\hline \multirow[t]{7}{*}{ arriba de } & el avión & 1.510 & 29 & 23 \\
\hline & el tren & 1.680 & 20 & 20 \\
\hline & el micro & 268 & 15 & 15 \\
\hline & el colectivo & 364 & 20 & 18 \\
\hline & el auto & 3.540 & 39 & 34 \\
\hline & la moto & 22.800 & 14 & 14 \\
\hline & la bici & 9.800 & 11 & 9 \\
\hline
\end{tabular}

Cuadro 3. Cantidad de ocurrencias estudiadas 


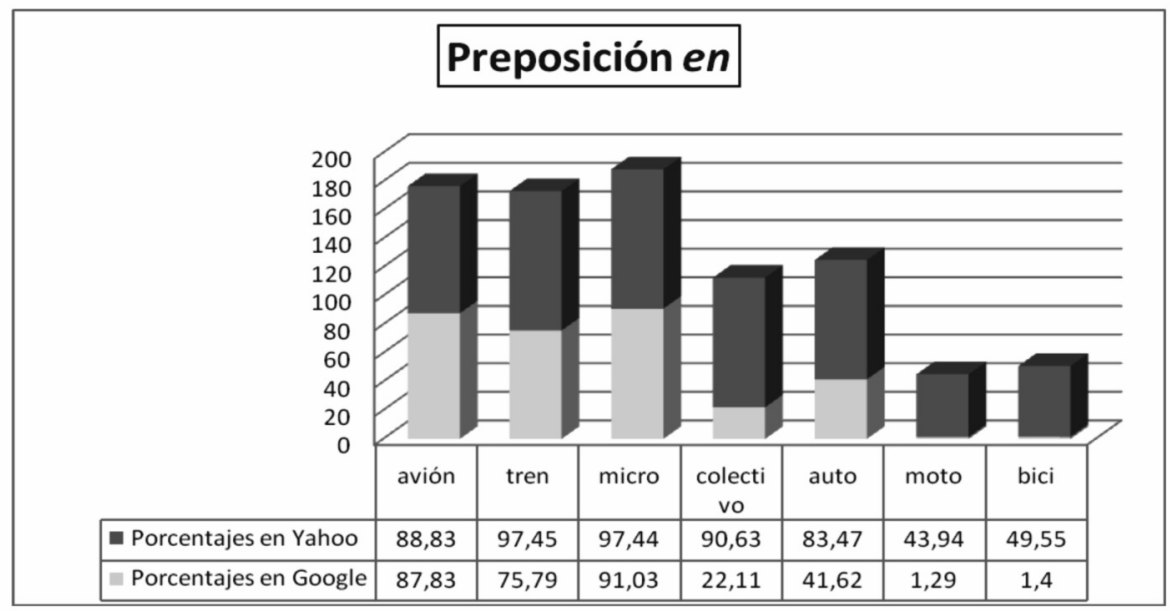

Cuadro 4. Frecuencias de uso de la preposición en+medio de transporte

(13) Estoy en el tren de camino a Stockholm, ya llevamos casi 5 dias de vacaciones aquí en Suecia donde he estado totalmente desconectado ya que no hay wifi ni

(14) Ahora estoy en el auto yendo "al norte" que acá es algo así como decir "el interior"... es esa nebulosa que queda afuera de capital

(15) hola gente,como andan,bien, bueno aca estoy en el colectivo cuando me fui de viaje a buenos aires, estaba alpe 2 y me saq esta foto q les dejo aca para q me la

(16) y no hay un dia igual, un dia estoy en la moto de arriba y abajo de la ciudad de Mexico, otro dia estoy limpiando alfrombras,

(17) Tras subir las maletas lo tengo muy claro. Me cambio y a las seis estoy en la bici para subir el Col de Pal. Vamos a matar la tarde conociendo este puerto.

Por motivos extralingüísticos, la frecuencia de este dato decrece según el siguiente orden: avión, micro, tren, auto, colectivo, moto, bici.

Aparece asimismo, aunque con menor importancia, una descripción de entorno. Así, en el caso de en el avión, para 16 indicaciones de destino ("Ahora mismo estoy en el avión y de camino a Shanghai"), se registran 7 referencias al interior de la cabina ("Ya estoy en el avión, un airbus 330. Me toca al lado de un chico muy simpatico. El vuelo dura 12 horas y es muy tranquilo, aunque aburrido") y algunas mixtas ("Estoy en el avión, entre Sao Paulo y Frankfurt, empotrado y totalmente embutido al lado de la ventana pero.... iijreclinado!!!"). En cambio, los SN el colectivo o la moto, por ejemplo, coocurren en número mayor con descripciones de entorno o posición ("Estoy en el colectivo, camino a casa. La temperatura de casi $38^{\circ} \mathrm{C}$ o mas, y mucha gente alrededor. Por mas que esté sentada, la incomodidad por el calor..." " aki estoy en la moto..dandome unas vueltas..con mi gran amigo esteban"). 
Es decir que en se posiciona como relacionante general, con focalización variable de localización geográfica y evocación de entorno, en coincidencia con la variedad de grados de especificación señalada en 2.2.1.

Adicionalmente, se consignan las siguientes observaciones:

- la secuencia estoy en el tren aparece en cuatro ocasiones con sentido figurado ("Si, estoy en el tren del amor esperando un destino que no se donde me llevara ; Con mucho gusto me bajaria cuanto antes pero no quiero dar...");

- se registran dos casos de sentido divergente con el objetivo de la búsqueda: el micro aparece en seis oportunidades como designación del microcentro porteño ("hola si le queda 9 meses de garantia, estoy en el micro centro a 4 cuadras del obelisco, salu2") y el colectivo remite en cinco ocasiones a una organización de personas con un objetivo común ("Estoy en el colectivo LA PANKTERA ROSA, milito en este joven colectivo desde el principio. Va en aumento en militantes y ya hemos hecho algunas cosillas");

- estoy en la bici corresponde a medio de transporte en 21 casos de los 35 estudiados: los 14 enunciados restantes remiten a la bicicleta fija del gimnasio, sentido que puede influir en los demás elementos copresentes en los enunciados ("O mientras estoy en la bici, me coloco frente al Pc, y abro una presentación en el Power Point con fotos de cuerpos impresionantes. Funciona!").

\subsubsection{Las locuciones dentro de y adentro de}

De modo congruente con su especificidad, el empleo de los términos configuracionales dentro de y adentro de se limita a los contenedores (avión, tren, micro, colectivo, auto) y no se combina con soportes (moto, bici). Veamos primeramente la frecuencia de la locución dentro de.

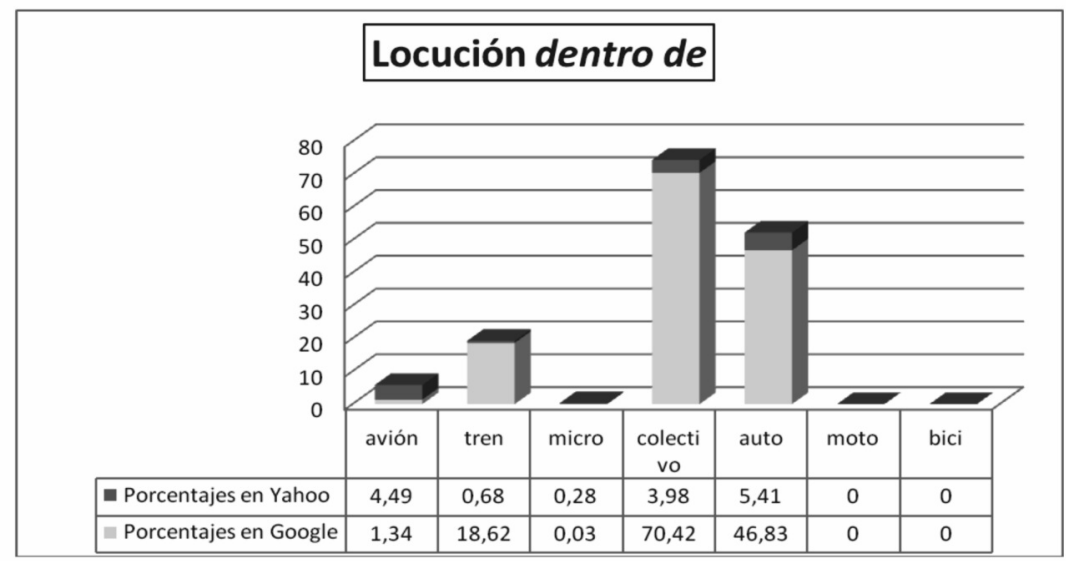

Cuadro 5. Frecuencias de uso de la locución dentro de+medio de transporte 
Cuantitativamente, dentro de registra una frecuencia media y, en general, salvo con colectivo y auto en Google, no sobrepasa el empleo de en. Sin embargo, como lo hemos señalado, en su coocurrencia con colectivo, el sentido "grupo de personas" puede activar un énfasis en la inclusión que justificaría la elevada cantidad de empleos (5.750) registrados en Google. Existiría pues un efecto de sobre-representación de la secuencia. Refuerza esta hipótesis el hecho de que de los doce enunciados disponibles en el buscador, solo uno remite al transporte público ("Yo mas de una ves analizo la forma de robarles el cel y salir corriendo..pero como generalmente estoy dentro del colectivo, se complica lo de salir"): los once restantes refieren al sentido "organización": "Pues referente a otras actividades estoy dentro del colectivo de artistas "Pensar es gratis", somos diseñadores, ilustradores, fotógrafos". Calculamos pues que la cantidad de empleos legítimos de dentro del colectivo como medio de transporte, debe ser sensiblemente inferior y acercarse a las cifras provistas por Yahoo (14 ocurrencias, 3,98\%).

En cuanto al análisis cualitativo, vale señalar la escasez de indicaciones de localización geográfica y la predominancia de escenas descriptivas del entorno inmediato, lo cual confirma el carácter de configurador de interioridad de la locución dentro de.

(18) Ya estoy dentro del avión. Me siento y me coloco el cinturón de seguridad. Tengo que cubrirme la boca para disimular una sonrisa al acordarme del escándalo (19) Me parece mentira, estoy dentro del avión, cómo si fuese algo que hago cotidianamente. ESTOY TOTALMENTE FAMILIRIZADA CON TODOS LOS BOTONES, AIRE, LUCES.

(20) Él escribió: «Ya estoy dentro del tren. Las butacas son cómodas. El servicio es bueno. A cada instante, durante todo el viaje, dentro y en las estaciones

Gana importancia la inclusión de la figura en la base y aparecen los límites de la entidad contenedora. Tal inclusión de la figura en un contenedor, ilustrada por enunciados como

(21) Ahora estoy dentro del avión, estoy nervioso ya que es la segunda vez que me meto en un avión. Te hago la carta para diristraerme. Te he hechado mucho de menos

(22) Abro los ojos y estoy dentro del auto y el asiento me aprieta el pecho contra el volante. Y arriba -porque adelante es arriba-está papá,...

puede incluso aludir al encierro:

(23) Cuando estoy dentro del avión siento que me vuelvo loca, que me quedo sin aire, que me ahogo, que necesito que me vea un doctor... 
(24) Veronica: Una vez que yo estoy dentro del avión, tengo que salir, empiezo a transpirar, siento que me falta el aire, ¿eso no es pánico...

Con respecto a la locución adentro de, cabe resaltar su presencia decididamente marginal, siempre menos del $1 \%$.

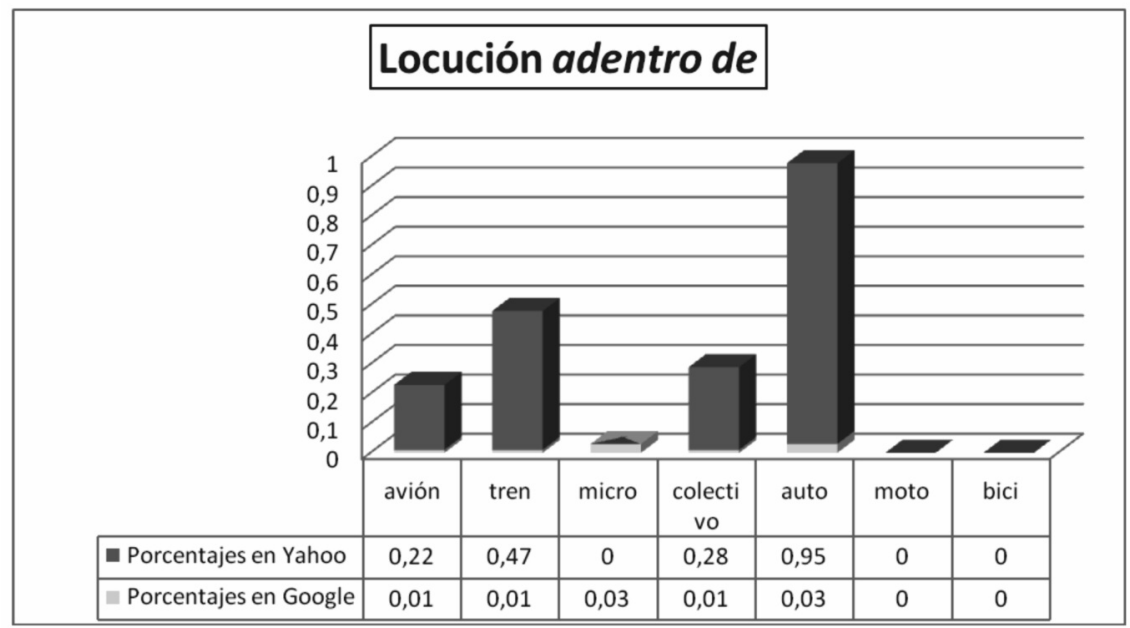

Cuadro 6. Frecuencias de uso de la locución adentro de+medio de transporte

Al igual que dentro de, adentro de configura interioridad

(25) Si quieren comprobar que es mio, vean la foto que puse en mi espacio de MSN a donde estoy adentro del auto... no apoyado solamente como el gil de mi...

y descripción del entorno inmediato:

(26) Estoy adentro del avión y el sonar de los motores es ensordecedor. Al ver a mí alrededor, veo soldados de muchas nacionalidades, que incluyen alemanes...

(27) En ese momento tenía tres años y estoy adentro del auto con mi mamá. Apenas se ve su silueta en el asiento del copiloto. Ni ella se acuerda por qué decidió..

A título informativo se observa que la secuencia "estoy dentro del tren" aparece en tres ocasiones con sentido figurado ("Las Cotizaciones del Mercado Continuo, Información financiera, gráficos bursátiles, foro de bolsa ok. Yo estoy dentro del tren, aunque no sé si duraré mucho").

De lo expuesto concluimos que los relacionantes dentro de y adentro de, con marcada fuerza descriptiva, configuran escenas de interioridad en las que figura y base aparecen ligadas por una relación explícita de tipo continente/contenido. Ello se percibe por la nitidez con la cual ambos términos figuran los límites del contenedor percibidos y mostrados por el enunciado. El empleo de 
ambos marcadores espaciales (en coocurrencia con contenedores) resulta pues congruente con sus instrucciones interpretativas.

4.2.3. La preposición sobre y las locuciones encima de y arriba de

4.2.3.1. Sobre y encima de

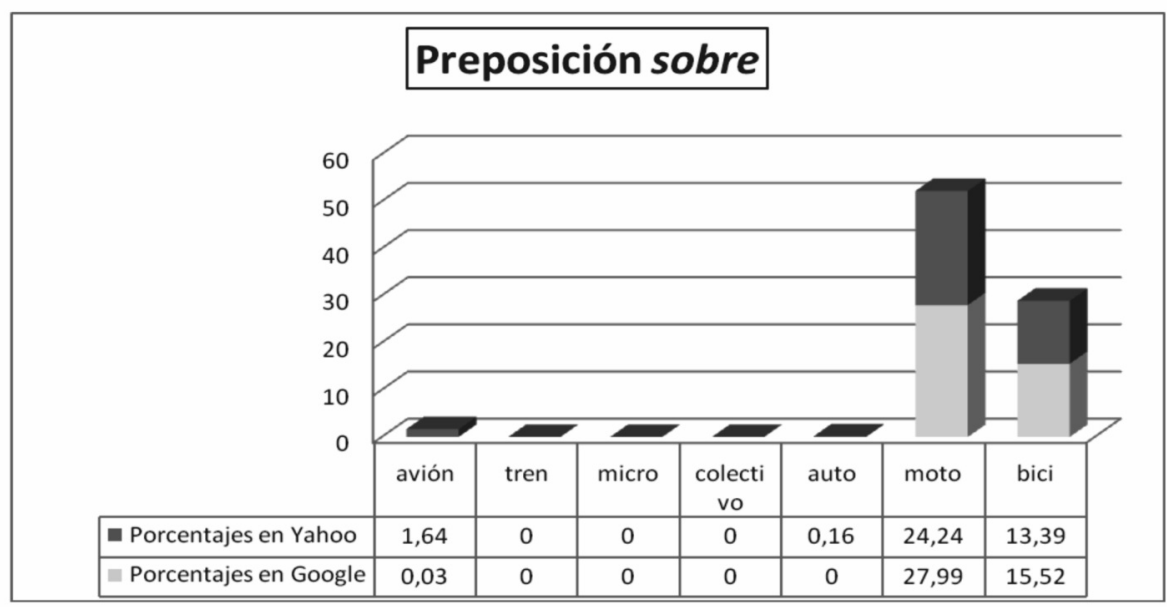

Cuadro 7. Frecuencias de uso de la preposición sobre+medio de transporte

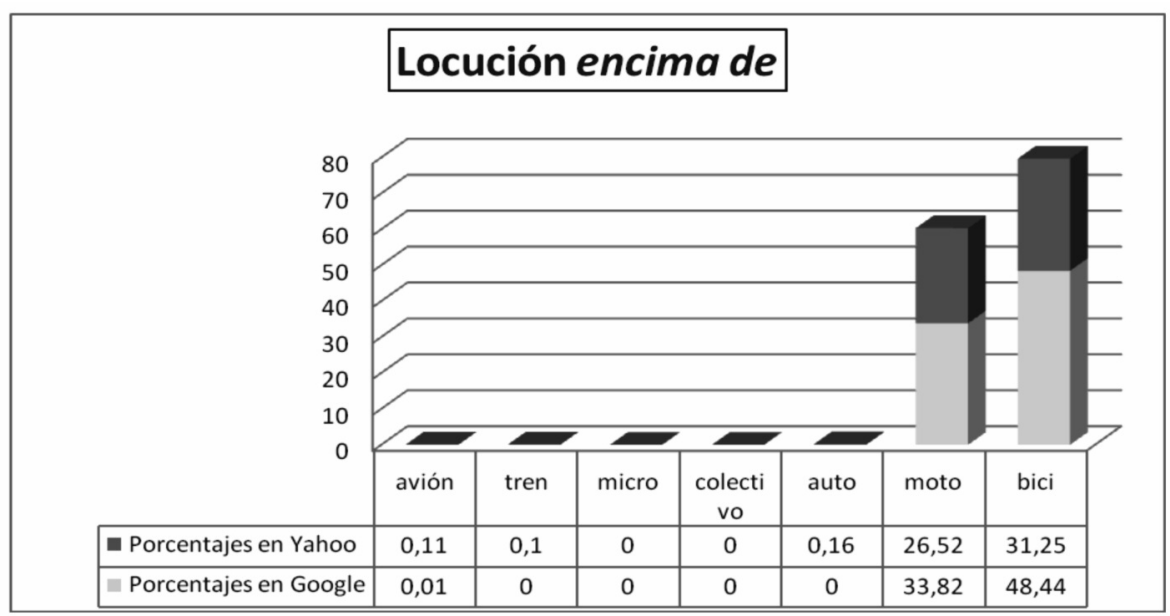

Cuadro 8. Frecuencias de uso de la locución encima de+medio de transporte

Cuantitativamente, los relacionantes sobre y encima de muestran una marcada congruencia con los SN estudiados: coocurren únicamente con soportes 
(moto, bici) en porcentaje elevado. En este caso, parece existir una predominancia de encima de que exhibe una mayor frecuencia de uso. No se registran coocurrencias con contenedores, salvo 1,64 \% en Yahoo para sobre el avión.

El estudio cualitativo muestra la escasa combinación de sobre con contenedores. Según el análisis de los enunciados disponibles, la preposición, con tres ocurrencias, aparece en un único empleo con el sintagma el avión para la indicación de viaje ("Estoy sobre el avión, y acabamos de partir desde Perú. Les cuento que llegué al aeropuerto con dos maletas de 45 y 48 kilos..."). En los dos casos restantes, el contexto parece sugerir alusión a un juego en pantalla o a una descripción de tipo onírico: "estoy sobre el avión, planeando sobre el mapa. La cuerda en la mano y el viento en la cara. Bienvenido a las planicies de Ganímedes".

No se registra ningún empleo con tren, micro, colectivo. La única ocurrencia con el sintagma el auto parece configurar una descripción de soporte: "En la foto estoy sobre el auto de mi padre, en agosto de 1952, frente a nuestra casa en la calle Iquitos 370, Chosica. Vivíamos frente a la casa de los...". El contexto sugiere la imagen de un niño pequeño sentado sobre el capot de un auto, en una pose característica de las fotografías familiares de la época. Es decir que sobre, como lo hemos señalado, coocurre raramente con contenedores pues sus instrucciones interpretativas remiten a configuración de soporte.

La locución encima de muestra el mismo comportamiento. Se registra un solo empleo con los sintagmas el avión, el tren y el auto en clara alusión a juegos en pantalla, evocando el posicionamiento del cursor sobre las imágenes:

(28) hola estoy atascada en la pantalla de los planetas y no se como llegar hasta jimbo estoy encima del avion que ay y no logro llegar a ningun sitio mas

(29) Ya lo he intentado todo: seguir el camino sin salirme, darle a B cuando estoy encima del tren, es q parece q el tren me echa para el lado!

(30) En esta parte yo no manejo el que maneja es connor y yo estoy encima del auto y ella esta atras de nosotros persiguiéndonos

No se registra ningún uso con micro o colectivo. En cambio, ambos marcadores de superposición coocurren frecuentemente con moto y bici. En este caso, su uso no está asociado a indicación de destino del desplazamiento, como en el caso de en, sino que aparecen alusiones a la posición física:

(31) cuando estoy sobre la moto me noto con la espalda encogida, a veces pruebo coger los semimanillares del extremo final y voy mas comodo y pensando pues

(32) Así que voy a tomar medidas exactas de los ángulos de mis articulaciones cuando estoy sobre la bici y afinar mi posición esperando que eso ayude a que el 
e incluso al dolor físico, nociones ausentes de los enunciados localizadores compuestos con la preposición en.

(33) La muñeca izquierda y el dedo índice me siguen doliendo cuando estoy sobre la moto, y los neumáticos no han mejorado la situación

(34) Puedo soportar el dolor en mi tobillo derecho cuando estoy sobre la moto, aunque tengo que utilizar muletas para caminar

(35) Cuando estoy encima de la moto, es un problema cuando me viene la descarga de dolor fuerte», decía. Reposo, hielo y antiinflamatorios son la

(36) Cuando estoy encima de la moto, los tobillos me molestan mucho. El izquierdo (sufre una pequeña fractura en el maléolo) porque es con el que reduzco marchas

(37) Es un dolorcillo tipo punzada, molesto mas que doloroso, que se va incrementando a media que estoy sobre la bici o cuando fuerzo un poco mas

(38) Es muy incomodo cuando estoy encima de la bici, no me duele me molesta pero a los 5 Minutos de bajarme me duele muchisimo.

Dentro de un contexto de comentarios relativos a la mecánica (moto)ciclística, los configuradores sobre y encima de aparecen describiendo el peso físico, noción de carga inherente a la configuración de superposición.

(39) El tema es así: pasan bien los ochos piñones cuando la estoy ajustando y la tengo levantada, pero cuando esta en el piñon 3 o 4 y estoy encima de la bici

(40) Ponga la presión que le ponga,cuando estoy encima de la bici la horquilla no se hunde nada. Cuando le pongo menos presión, se me hunde mas al montame, pero una"

Concluimos que, a diferencia del localizador en, los marcadores sobre y encima de participan de enunciados con mayor fuerza descriptiva: figura y base aparecen ligadas por una relación de superposición. Ello se percibe por la nitidez con la cual ambos términos figuran los condicionamientos de posición impuestos por las características de las entidades en juego. El empleo de ambos configuradores (en coocurrencia con soportes) es por tanto congruente con sus instrucciones interpretativas.

Así pues, parecería confirmarse una división de tareas entre la preposición en, predominantemente localizadora, cuya abstracción queda en evidencia por su diversidad de empleos, y los configuradores dentro de/adentro de y sobre/encima de. Las locuciones prepositivas de interioridad coocurren con contenedores y contribuyen a la evocación de límites. Los relacionantes de superposición se combinan con soportes y aluden a la noción de carga. Veamos ahora lo que sucede con la expresión arriba de. 
4.2.3.2. Arriba de

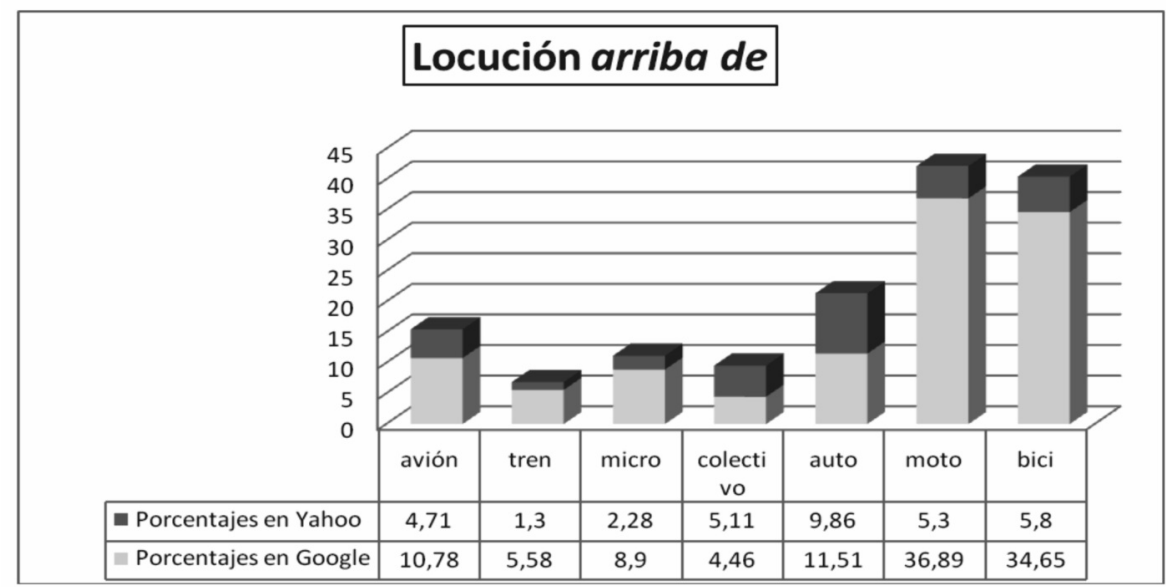

Cuadro 9. Frecuencias de uso de la locución arriba de+medio de transporte

La locución aparece en empleo congruente con soportes en cuarto lugar en Yahoo y en primera y segunda posición en Google. El empleo del relacionante no registra mayores diferencias con los usos de sobre y encima de y aparece como marcador de superposición:

(41) cada vez que me subo a mi moto gozo la vida en aquellos instantes y cuando no estoy arriba de la moto aprovecho al maximo a mi familia...

Sin embargo, un elemento llamativo es la presencia de arriba de en segunda y tercera posición con contenedores en porcentajes que, en Google por ejemplo, van del 4,5\% al 12\%, fenómeno que distingue a esta expresión de los otros dos indicadores de superposición. En efecto, la locución emerge como relacionante espacial con medios de transporte que inducen interioridad tales como, en orden decreciente, auto, tren, avión, colectivo, micro.

Cabe preguntarse si esta combinación corresponde a una configuración de superposición de la figura sobre una base con características de contenedor del tipo "La valija está arriba del auto" (si se encuentra en el portaequipajes) o "El frasco de perfume está arriba de la cómoda" en alternancia con sobre/encima de.

Un estudio cualitativo de los enunciados disponibles revela que el relacionante interviene con baja frecuencia en configuraciones portador/portado cuando el portador es un contenedor. Existen, en nuestro corpus, escasas ocurrencias de este tipo de empleo: 
(42) Estoy arriba del auto. En un árbol. Sarah trepó a un árbol cercano cuyas ramas se extendían sobre el Explorer. Eligió una rama que parecía flexible ${ }^{6}$

En la mayoría de los casos, arriba de localiza en el interior del vehículo. Así, los empleos registrados muestran afinidad con las características de los enunciados locativos con la preposición en: aparecen indicaciones de destino y/o de ubicación:

(43) Estoy arriba del auto, camino a Viña del Mar. Es 14 de febrero y hasta la gente de los peajes mira con complicidad a las parejas enamoradas

(44) Estoy arriba del tren 4480 Bordeaux Lyon, voiture 11, place 24, non fumeur, todo bajo control, puedo relajarme, un poco, siempre hay que estar alerta

(45) LES CEUNTO QUE ME VOY DE VIAJE DE VENTA A MAR DEL PLATA , YA ESTOY ARRIBA DEL MICRO, JEJE. SIGANLA ROMPIENDO EN CUALQUIER PÀRTE DEL PAIS

(46) Estoy arriba del colectivo 24, y cada movimiento me hace fantasear con que suena el celular. No suena. Me bajo en San Telmo, como siempre, y miro la hora

Paralelamente se registran, así como con el localizador en, descripciones del entorno inmediato:

(47) y a no me importa tanto porque estoy arriba del auto con la ventana abierta y el viento me pega en la cara mientras vuelvo a casa con los ojos cerrados

(48) Ya estoy arriba del tren. Al comprar el pasaje olvidé pedir específicamente un asiento que no quedara de espalda al sentido de marcha, asi que

(49) Ya estoy arriba del avion, y como les contaba a la venida, en los vuelos domesticos no dan comida, sino que cobra, us $\$ 5$ por un sanguche y us $\$ 3$ por unos

(50) Ya estoy arriba del micro. Aunque pague ejecutivo es cama suite! Esta por arrancar. Espero tener buen viaje. Nos vemos en pocas horas, mi amor

(51) Ya estoy arriba del colectivo ...y ya conociendo las caras de quien viaja conmigo todos los dias....que es una ventaja....y me posiciono al lado de la mujer

A ello se suma un rasgo de empleo específico aunque el reducido número de ocurrencias no permita considerarlo como definitorio: la coocurrencia con la marcación del inicio del viaje o la anticipación de la partida, especialmente notable en la secuencia arriba del avión:

(52) El solo hecho de tener los tickets en la mano me hace sentir que ya estoy arriba del avión. Realmente tengo que cuidarlos mucho ya que son mi única compañía

(53) Y ya estamos en noviembre!! y ya pasó mi cumple! y Queda un mes pa irme a gringolandia!!! AAh!! Ya estoy arriba del avión... tengo la mente en otras

$6 \quad$ En este caso, se registra superposición sin contacto. 
(54) Buenos saludos a todos porque en una hora estoy arriba del avión. Nos vemos en el liceo

(55) Unas cuantas horas más y estoy arriba del avión! Anyway, esto es solo una prueba para ver que esto funciona y que puedo postear desde el iPhone

(56) Faltan solo 48 h y estoy arriba del avión!!!! Estoy desesperado, ya no me puedo ni concentrar

De lo expuesto se concluye que arriba de + medio de transporte se aparta del comportamiento prototípico de los configuradores de superposición sobre y encima de y se aproxima a una localización abstracta en competencia con en -prueba de ello es su coocurrencia con todos los medios de transporte.

Como hemos visto, su predominante congruencia con soportes no inhibe su asociación pragmática con contenedores. Resta explicar este desplazamiento y analizar el aporte específico de esta formulación con respecto a los enunciados localizadores prototípicos con la preposición en. ¿Cómo modelizar este comportamiento que parece contradecir la configuración canónica de la escena espacial? Una primera opción sería la aplicación de la noción de zonas activas de Ronald W. Langacker (1987).

\section{Modelización de este fenómeno preposicional}

\subsection{Análisis según el concepto de zonas activas}

El autor de Foundations of Cognitive Grammar (1987: 272) define como zonas activas (active zones) las porciones de los argumentos del enunciado que participan directamente de una relación dada, por ejemplo:

(57) Su perro está cerca de mi gato

(58) Su perro mordió a mi gato

En (57) participan dos totalidades indiferenciadas mientras que en (58) la relación parece implicar especialmente algunos aspectos de estas entidades: los dientes del perro y una parte del gato, sin que se establezca discontinuidad con zonas no activas. Aunque este principio puede aplicarse a diferentes tipos de asociación, las zonas activas remiten frecuentemente a algunas partes de un todo, en una relación de sinécdoque.

Desde este punto de vista, podría considerarse que estoy arriba del auto activa zonas diferentes a estoy dentro del auto: no ya la carrocería sino el chasis y las ruedas. De este modo el vehículo no sería visto como contenedor sino como soporte, conceptualización que justificaría la elección de un relacionante congruente.

Ahora bien, la activación de una configuración de soporte, convocaría indicadores de superposición, es decir que, verosímilmente, junto a los enun- 
ciados con arriba de aparecerían, aunque fuera de modo incipiente, formulaciones concurrentes con sobre y encima de, tal como sucede en el caso de la moto y la bici. Sin embargo, no es así. La evidente falta de alternancia entre los tres relacionantes de superposición con los vehículos cerrados vuelve dudosa la aplicación del principio de zonas activas para explicar este empleo.

Consideramos que una explicación satisfactoria podría encontrarse en la noción de encuadre de escena verbal y, particularmente, el concepto de fuera de cuadro o fuera de campo.

\subsection{Aplicación de la noción de fuera de campo}

\subsubsection{La escena verbal}

La integración de sistemas proposicionales y no proposicionales dentro de nuestra matriz cognitiva general (Jackendoff, 1983; Langacker, 1987) permite concebir una asociación entre verbalización y sistemas imaginísticos (Talmy, 1983, 2000) como modos de representación diferentes para un mismo universo representado. Aunque no pueda hablarse de correspondencia unívoca, la relación evidente entre ambos sistemas (las representaciones mentales participan en la producción del discurso o se activan a partir de soporte lingüístico) permite explorar ciertas relaciones entre verbalización y conceptualización. Como lo afirma Laurent Gosselin (1996, 2005), ambos sistemas intervienen en un proceso de percepción/mostración en el que la visualización se integra a la enunciación como manera de ver y dar a ver aquello de lo que hablamos.

La lingüística se sirve de tal relación y, para aprehender las representaciones mentales, recurre con frecuencia a un analogon físico. Tal es el caso de la noción de escena verbal (Victorri y Fuchs, 1996; Victorri, 1997, 1999) que, asocia los recursos del lenguaje a la panoplia de medios técnicos de la cinematografía.

Bernard Victorri define la escena verbal como la construcción por el locutor de un espacio exterior a sí mismo dentro del cual, da a ver el objeto de su discurso como si se tratara de una escena proyectada ante sus interlocutores: el locutor sitúa la cámara donde desea llevar a su auditorio, puede a su voluntad seguir el desarrollo de la acción, volver atrás, saltar hacia el futuro, focalizar un detalle o alejarse, ponerse en el lugar de alguno de los personajes, etc.

"Construidas en y por el discurso" (Victorri y Fuchs, 1996: 201), estas imágenes adquieren una existencia fenomenológica compartida por varios sujetos dentro de un campo intersubjetivo que resulta del habla y posee la capacidad de hacer surgir entidades y procesos ante los interlocutores. Tales imágenes, surgen en un campo definido por el sujeto, según un encuadre particular, según su ángulo visual o el de su ojo mental (Talmy, 1983). 


\subsubsection{Fenómenos de encuadre}

Para la presentación de la escena, el sujeto procede entonces a un recorte de una porción de lo mostrable, definiendo un campo de observación dentro del cual opera un encuadre determinado. Se determina así un campo poblado de entidades, más o menos salientes, según una dinámica de figura-fondo.

El cuadro, límite exacto del campo, es la ocasión de un juego entre espacio interior y exterior. Por un lado, lo que se encuentra en cuadro dentro de la imagen y, por otro, el fuera de cuadro o fuera de campo, es decir lo que no se encuentra en el campo visual, como resultado de un encuadre. Para Gilles Deleuze, el fuera-de-campo no es una negación: remite a lo que no se oye ni se ve, pero se encuentra perfectamente presente (1983: 28, énfasis propio).

¿Cómo relacionar encuadre, cognición y fenómenos lingüísticos? La operación de recorte y selección atraviesa las reflexiones sobre la percepción, la cognición y el lenguaje: la determinación de un encuadre particular correlato de fenómenos del campo atencional no es ajena a la construcción del sentido de un enunciado. Así, Leonard Talmy (2000) vincula explícitamente el windowing of attention (es decir la inclusión $u$ omisión de elementos de una escena) a la introducción/ omisión de material lingüístico explícito. El dispositivo de Talmy supone la determinación de una ventana con bordes más o menos precisos que definen una región de coherencia, co-importancia y conectividad (2000: 305) así como una dicotomía windowing-gapping generadora de una disyunción entre mostrado y omitido.

Nuestro dispositivo de análisis hará operatoria esta disyunción bajo la forma de una tensión entre en-cuadro y fuera-de-cuadro. Y, fundamentalmente, agregará el concepto de Gilles Deleuze, la presencia de lo no visto.

\subsubsection{Modelización del empleo arriba de + medio de transporte contenedor}

Según nuestro dispositivo de escena verbal, distinguiremos, para una misma escena, dos puestas en imagen diferentes:

- estoy en el avión construye un cuadro que comprende la figura (el sujeto humano) y la base (el avión). El enunciado muestra una simple relación de localización inducida por la preposición en.

- estoy arriba del avión pone en imagen la figura, la base y la relación de localización. Pero a ellas agrega la evocación del fuera-de-campo (Deleuze, 1983) es decir aquello que, sin ser percibido directamente, se intuye y aparece en un juego de relaciones implícitas.

¿En qué consiste esta presencia? En la praxis de ascenso al vehículo inducida por arriba de, término que en su uso adverbial integra una visión dinámica. En efecto, existe una fijación experiencial y cultural del movimiento 
ascendente: se sube a un avión/tren/micro/colectivo/auto, dentro del frame (Fillmore, 2006 [1982]) correspondiente al viaje. El uso del adverbio se encuentra pues cognitivamente asociado a la rutina de ascenso a un vehículo (¡Arriba!). La alta frecuencia de activación de esta práctica facilita la fijación lingüística de la locución arriba de que visibiliza, implícitamente, el desplazamiento efectuado por la figura. Tal presuposición, sobre la base de un elemento presente en el enunciado (Ducrot, 1984: 13-46), pone en relieve el potencial de inferencia de este relacionante: cuando un pasajero dice estar arriba del avión, no se encuentra sentado sobre el ala o sobre el fuselaje sino que se halla dentro de la cabina después de haber subido a la aeronave. En efecto, arriba del avión/tren/etc. no configura una escena espacial de superposición sino que localiza a-descriptivamente la figura al término de un movimiento implícito, es decir, presente fuera de cuadro.

Así parecen sugerirlo algunos enunciados de nuestro corpus de estudio en los que cabe resaltar la aspectualidad del movimiento realizado fuera de cuadro sugerida por el empleo del adverbio ya:

(59) me dice que vamos al auto a dejar unas cosas y en eso cuando ya estoy arriba del auto veo que al otro lado de la calle está esta belleza en un Holden

(60) Siempre me acuerdo en ese momento de lo mucho que lo quiero y le digo que lo amo mucho, el problema es que estoy arriba del auto y él ya no me escucha

(61) y digo lo tengo que lubricar, pero me da fiaca ya que ya estoy arriba del auto, y despues cuando me bajo me olvido

(62) Ya estoy arriba del tren. Al comprar el pasaje olvidé pedir específicamente un asiento que no quedara de espalda al sentido de marcha, asi que

(63) Ya estoy arriba del avion, que para mi es señal de que puedo relajarme. Historicamente, lo que podia salir mal ya no salio mal

(64) Ya estoy arriba del micro! Como siempre llegue de pedo, a las corridas, pero igual ya empieza el viaje. Gracias vecinas por la mochila y la rĩ̃̃onera (riñonera)

(65) Ya estoy arriba del micro. Aunque pague ejecutivo es cama suite! Esta por arrancar. Espero tener buen viaje. Nos vemos en pocas horas, mi amor

(66) Obviamente, ya estoy arriba del colectivo y no hay demasiadas posibilidades de regresar por abrigo, ni paraguas

(67) No me creo nada, hasta que no estoy arriba del avión, cuando voy a viajar, cuando estoy en alguna cobertura. Y no creía que me fueran a reconocer

\section{La pregnancia del eje vertical}

Por último, deseamos señalar ciertas diferencias de accesibilidad de las dimensiones espaciales en un referencial egocéntrico que depende de propieda- 
des morfológicas y funcionales de nuestro cuerpo (De Vega y Rodrigo, 1997: $54,66)$.

A diferencia de los sistemas de orientación llamada absoluta (regidos por los puntos cardinales), el sistema de orientación relativa considera el espacio en términos de coordenadas establecidas por un plano vertical definido por la fuerza de gravedad y un plano horizontal, perpendicular al primero, cuya representación más significativa nos es dada por la superficie de la tierra (Miller y Johnson-Laird, 1976).

El plano vertical goza de un estatus perceptual excepcional por nuestra experiencia cotidiana de seres terrestres sujetos a la ley de la gravedad. A este respecto, Miller y Johnson-Laird (1976: 62) señalan que la distinción arribaabajo aparece más temprana y claramente que la distinción, a nivel horizontal entre adelante-atrás y derecha-izquierda.

Las coordenadas del plano horizontal, dominadas por una visión antropocéntrica, se organizan según las propiedades anatómicas del ser humano: el eje asimétrico frente-espalda genera la distinción adelante-atrás que se encuentra fuertemente anclada en nuestra percepción. En cambio, la simetría bilateral da lugar a un eje derecha-izquierda que, justamente por su simetría se presta a alineaciones ambiguas. Así lo prueban las experiencias efectuadas por N. Franklin y B. Tversky (que citamos según De Vega y Rodrigo (1997: 54-66). En pruebas de localización de objetos según un texto descriptivo, los tiempos de respuesta de los sujetos varían según las dimensiones activadas: los objetos situados en la dimensión arriba-abajo suscitan respuestas más rápidas que los que se encuentran situados en el eje adelante-atrás. A su vez, estos últimos inducen respuestas más rápidas que los objetos situados en el eje derecha izquierda. A esto puede agregarse una asimetría en el eje adelante-atrás: los objetos ubicados delante del sujeto suscitan respuestas más rápidas que los ubicados atrás.

La puesta en palabras no permanece ajena a nuestro sistema de orientación. Aparece una correlación entre empleo de unidades lingüísticas y conceptualización del espacio, principalmente en lo concerniente a la orientación vertical. Así, la búsqueda de la secuencia "estoy arriba del subte" arrojó una sola ocurrencia en Google. Consideramos, intuitivamente, que la fijación de niveles en el eje vertical puede trabar, aún inconscientemente, la asociación entre movimiento ascendente (subir) y un medio de transporte subterráneo.

Cabe resaltar, además, la existencia de una asimetría: así como aparece una mayor accesibilidad en el eje horizontal a lo que se encuentra delante del sujeto,

7 La expresión designa, en Buenos Aires, un tren subterráneo de circulación urbana. 
en el eje arriba-abajo se perfila una preferencia por el movimiento ascendente, connotado positivamente. En efecto, la emergencia del empleo arriba de no se encuentra acompañada de un empleo paralelo de la expresión conversa abajo de + medio de transporte. La formulación estoy abajo del avión/tren/etc. (con inferencia potencial "bajé" o incluso "llegué") registra un escaso número de ocurrencias tanto en Google (G) como en Yahoo (Y), apenas un total de 14 vs 40.145 para arriba de.

\begin{tabular}{|l|l|l|l|l|l|l|l|}
\hline & Avión & Tren & Micro & Colectivo & Auto & Moto & Bici \\
\hline Estoy & G:1.510 & G: 1.680 & G: 268 & G: 364 & G: 3.540 & G: 22.800 & G: 9.800 \\
arriba de & Y: 43 & Y: 25 & Y: 8 & Y: 18 & Y: 62 & Y: 14 & Y: 13 \\
\hline Estoy & G: 0 & G: 2 & G: 0 & G: 0 & G: 7 & G: 0 & G: 0 \\
abajo de & Y:0 & Y: 1 & Y:0 & Y:0 & Y: 4 & Y:0 & Y:0 \\
\hline
\end{tabular}

Cuadro 10. Frecuencias de uso: contraste abajo de/arriba de+medio de transporte

Las dos ocurrencias disponibles de abajo del tren corresponden a un empleo figurado más que a una configuración espacial concreta.

(68) nose. caca. todo mal. todo mal. todo. bue ja. chau ma, si m buscas estoy abajo del tren :) (?) "But now I'm high; running wild among all the stars above"

(69) En fin te encuentro toda la razon, muchas veces tbn siento q estoy abajo del tren, quizas en uno q va en sentido contrario, o simplemente caminando por las"

En el caso de abajo del auto, un solo empleo remite a la configuración de una escena espacial de superposición:

(70) UN WEON SE TABA GANANDO LAS MONEAS KON MIGO Y ME TIRO EL AUTO ENSIMA SI NO ES POR UNA AMIGA TOABIA ESTOY ABAJO DEL AUTO PEGA

En el resto de los casos, estoy abajo del auto no sugiere posición física del vehículo sobre el individuo, sino localización fuera del automóvil como expresión conversa de arriba del auto:

(71) buenisimo!!! ya estoy abajo del auto con la notbook. (mis vecinos creen que el auto es electronico por completo) jajaja

(72) Cuando me doy cuenta de mi vestimenta ya estoy abajo del auto con cara de loca encarando al chofer del camión. Yél y sus compañeros me miran el culo con

Nótese que en estos dos casos, también se sugiere movimiento acabado de descenso del vehículo reforzado por la aspectualidad del adverbio.

En algunos enunciados, la expresión conversa estar abajo del auto alude a una rutina. Si estar arriba del auto puede equivaler a conducir y eventualmente participar en competiciones deportivas, estar abajo del auto se define negativamente y puede sugerir tanto la interrupción de la actividad (correr, conducir) como la realización de una actividad complementaria fuera de la pista de carrera. 
(73) lo de los dos pibes que me conocen y me encubren cuando estoy abajo del auto, viste, eso de estar de un lado y que te guiñen del otro, la adultez

(74) Me pongo mal cuando estoy abajo del auto, pero hace mucho que corro. Además, no tenés vacaciones ni vida propia durante el verano.

(75) carrera arriba del auto que no alcanzo a sacar conclusiones para poder avanzar en las posiciones; cuando me quiero dar cuenta ya estoy abajo del auto

(76) un acompañante tiene mas de 10 funciones diferentes dentro del auto mas alla de brindar apoyo y seguridad a su piloto.... yo estoy abajo del auto pero sigo

\section{Conclusiones}

Nuestro estudio ha echado luz sobre un empleo particular de la locución prepositiva arriba de seguida de designación de un medio de transporte para localizar sujetos humanos: esta expresión participa tanto en enunciados configuracionales de superposición como en enunciados identificados como localizadores por su baja especificación descriptiva.

El análisis de los datos empíricos nos ha permitido arribar a las siguientes conclusiones:

i) La preposición en ostenta un alto grado de abstracción y variados niveles de especificación -su carácter localizador no inhibe la indicación de entorno-. Predomina su carácter localizador adescriptivo como lo prueban su marcada coincidencia con indicaciones geográficas y su coocurrencia con contenedores y soportes;

ii) Los relacionantes dentro/adentro de y sobrelencima de poseen un comportamiento semántico más específico: participan respectivamente en configuraciones de interioridad y superposición con sintagmas nominales congruentes;

iii) La expresión arriba de, de gramaticalización confirmada en Hispanoamérica, emerge como locución preposicional en proceso de abstracción. En efecto, sus empleos se aproximan a los usos de la preposición en: la formulación atenúa sus instrucciones configuracionales y exhibe una incipiente subespecificación pues se combina tanto con soportes como con contenedores para marcar localización;

iv) Arriba de se diferencia pragmáticamente de la preposición en: de marcada aspectualidad, los empleos de arriba de suelen sugerir el término de un movimiento ascendente. Tal presuposición ha sido modelizada en términos de encuadre, como movimiento fuera de cuadro. Este dispositivo coloca a la expresión como disparador de inferencias sobre la base del conocimiento común de la praxis del acceso a un vehículo.

v) Adicionalmente se observaron trazas a nivel lingüístico de la pregnancia cognitiva de la posición superior sobre el eje vertical: el contraste de frecuen- 
cias arriba de/ abajo de pone en relieve el anclaje de la rutina de ascenso, connotada positivamente.

Por supuesto, estas conclusiones tienen carácter provisorio. Resta proseguir nuestra exploración para afinar la descripción de la expresión estudiada y extender nuestro estudio a otros contextos de empleo. Tal empresa deparará sin duda revisiones y nuevos interrogantes.

\section{Referencias bibliográficas}

Cifuentes Honrubia, J. L. (1996): Usos prepositivos en español. Murcia, Universidad de Murcia.

Cifuentes Honrubia, J. L. (2003): Locuciones prepositivas. Sobre la gramaticalización preposicional en español. Alicante, Universidad de Alicante.

De Vega, M. y Rodrigo, M. J. (1997): "Les représentations topologiques dans le traitement des descriptions spatiales". En Denis, M. (eds): Langage et cognition spatiale. Paris, Masson, págs. 51-68.

Deleuze, G. (1983): Cinéma 1. L’image-mouvement. Paris, Les Éditions de Minuit.

Diccionario de la lengua española. Vigésima segunda edición. Real Academia Española: http://www.rae.es/rae.html (07-02-2010)

Diccionario Panhispánico de dudas. Primera edición. Real Academia Española: http://www.rae.es/rae.html (07-02-2010)

Ducrot, O. (1984): Le dire et le dit. Paris, Les Éditions de Minuit.

Franklin, N. \& Tversky, B. (1990): "Searching imagined environments", Journal of Experimental Psychology: General, 119, págs. 63-76.

Fillmore, C. (2006 [1982]): "Frame semantics". En Linguistic Society of Korea (ed): Linguistics in the Morning Calm. Seoul: Hanshin Publishing Company, págs. 111137. Reeditado en Geeraerts, D. (ed): Cognitive Linguistics: Basic Readings. Berlin: Walter de Gruyter GmbH \& Co, págs. 373-400.

García Pelayo y Gross, R. y Testas, R. (1967): Dictionnaire moderne français-espagnol, espagnol-français. Paris, Larousse.

Gili Gaya, S. (1973): Diccionario de sinónimos, Barcelona, Bibliograf.

Gosselin, L. (1996): Sémantique de la temporalité en français. Un modèle calculatoire et cognitif du temps et de l'aspect. Louvain-la-Neuve, Duculot.

Gosselin, L. (2005): Temporalité et modalité. Bruxelles, De Boeck \& Larcier, Éditions Duculot.

Grice, P. (1979): "Langage et conversation", Communications, 30, Paris, Seuil, págs. 57-72.

Herskovits, A. (1985): "Semantics and Pragmatics of Locative Expressions", Cognitive Science, vol. 9, 3, New Jersey, Ablex Publishing Corporation, págs. 341-378.

Jackendoff, R. (1983): Semantics and cognition. Cambridge, The Massachusetts Institute of Technology.

Langacker, R. W. (1987): Foundations of cognitive grammar. Volume 1, Theoretical Prerequisites. Stanford, Stanford University Press. 
Laur, D. (1993): "La relation entre le verbe et la préposition dans la sémantique du déplacement", Langages, 110, Paris, Larousse, págs. 47-67.

López, M. L. (1972): Problemas y métodos en el análisis de las preposiciones. Madrid, Gredos.

López de la Huerta, J. (1789): Examen de la posibilidad de fixar la significación de los sinónimos de la lengua castellana. Viena, Imprenta de Ignacio Alberti.

Miller, G. y Johnson-Laird, P. (1976): Language and Perception. Cambridge, Cambridge University Press.

Moliner, M. (1996): Diccionario de Uso del Español. Edición Electrónica, Versión 1.0. Editorial Gredos S.A.

Pottier, B. (1997): "Le cognitif et le linguistique dans l'expression des relations", Faits de Langues, 9, Paris, Ophrys, págs. 29-38.

REAL ACADEMIA ESPAÑOLA: Banco de datos (CREA) [en línea]. Corpus de referencia del español actual: http://www.rae.es (04-08-2010)

Rojo, G. (2010): "Aguja de navegar corpus", ponencia plenaria en el XII Congreso de la Sociedad Argentina de Lingüística (Mendoza, 6-9 de abril de 2010). En prensa en las Actas del Congreso: http://gramatica.usc.es/persoas/GuillermoRojo/Index/PublicacionesEnPrensa (04-08-2010)

Soto, G. (1996): "El papel de los esquemas en la representación de la información espacial por el lenguaje", Lenguas Modernas, 23, Universidad de Chile, págs. 25-48

Talmy, L. (1983): "How language structures space". En Pick, H. \& Acredolo, L. (eds), Spatial Orientation: Theory, Research and Application. New York, Plenum Press, págs 225-282.

Talmy, L. (2000): Toward a Cognitive Semantics. Volume 1. London, Cambridge, The MIT Press.

Vandeloise, C. (1986): L'espace en français. Sémantique des prépositions spatiales. Paris, Éditions du Seuil.

Vandeloise, C. (1990): "Les frontières entre les prépositions sur et à", Cahiers de Grammaire, 15, Toulouse, Université de Toulouse-Le Mirail, págs. 157-164.

Victorri, B. (1997): "La polysémie : un artefact de la linguistique?", Revue de sémantique et pragmatique, 2, págs. 41-62.

Victorri, B. (1999): "Le sens grammatical", Langages, 136, Paris, Larousse, págs. 85-105.

Victorri, B. y Fuchs, C. (1996): La polysémie. Construction dynamique du sens. Paris, Hermès. Wittgenstein, L. (1953): Philosophical Investigations. New York, The Mc Millan Co. 